\title{
Synthesis of kaolinite-filled EPDM rubber composites by solution intercalation: structural characterization and studies on mechanical properties
}

\author{
S. Ginil Mon • Y. Jaya Vinse Ruban • \\ D. Vetha Roy
}

Received: 15 June 2011 / Accepted: 27 July 2011 / Published online: 19 August 2011

(C) The Author(s) 2011. This article is published with open access at Springerlink.com

\begin{abstract}
In the large field of nanotechnology, polymer matrix-based nanocomposites have become a prominent area of current research and development. Exfoliated claybased nanocomposites have dominated the polymer world with excellent characteristics. EPDM rubber composites have been synthesized by solution-intercalation using the easily available kaolinite as filler. The composite structure has been elucidated by X-ray diffraction (XRD), Fourier transform IR, and scanning electron microscope studies. The molecular level dispersion of clay layers has been verified by the disappearance of basal XRD peak of kaolinite in the EPDM/kaolinite composites. The mechanical properties showed significant improvement of EPDM/ kaolinite composites with respect to neat EPDM.
\end{abstract}

Keywords EPDM - Kaolinite - Solution-intercalation · Morphology $\cdot$ Mechanical properties

\section{Introduction}

In the growing field of nanotechnology, polymer-matrix based nanocomposites have become a prominent area of current research and development. Reinforcing polymer matrices with fillers proves to be an effective tactics which will result in nanocomposites tailor-made for specific applications. Polymer composites are formed when phasemixing of effective fillers occurs within the polymer matrix. Due to the improved phase morphology and

S. Ginil Mon $(\bowtie) \cdot$ Y. Jaya Vinse Ruban · D. Vetha Roy Polymer Nanocomposite Centre, Department of Chemistry and Research, Scott Christian College (Autonomous), Nagercoil 629 003, Tamil Nadu, India

e-mail: therocksgm@yahoo.com interfacial properties, composites exhibit mechanical, thermal, barrier, and chemical properties superior to conventional polymers based on the fillers used (Giannelis 1996; Lan and Pinnavaia 1994; Uhl and Wilkie 2002; Agag et al. 2001; Messersmith and Giannelis 1993; Kojima et al. 1993; Usuki et al. 1993). Kaolinite, the most prominent clay material available in South India, is part of the group of industrial minerals, with the chemical composition $\mathrm{Al}_{2} \mathrm{Si}_{2} \mathrm{O}_{5}(\mathrm{OH})_{4}$. It is a layered silicate mineral, with one tetrahedral sheet linked through oxygen atoms to one octahedral sheet of alumina octahedral. Chemical modification of layered silicates has been previously reported through an ion-exchange reaction with $\mathrm{K}^{+}, \mathrm{Na}^{+}, \mathrm{Ca}^{2+}$, $\mathrm{Mg}^{2+}$, and organic cations such as alkyl ammonium ions to form the organo-silicate (Whittingham and Jacobson 1982). Exfoliated nanocomposites are obtained when the nanokaolin clay platelets are dispersed in the polymer matrix.

Ethylene propylene diene monomer (EPDM) is an unsaturated polyolefin rubber with a wide range of applications. Due to the absence of any polar groups on the backbone of EPDM, it is incompatible with the polar organophilic clay. Recent works have reported preparation of non-polar polymers clay-hybrids using functional oligomers (Kawasumi et al. 1997; Kato et al. 1997; Hasegawa et al. 1998; Hasegawa et al. 2000). Usukai et al. (2002) and Chang et al. (2002), respectively, have studied the mechanical properties of EPDM-clay nanocomposites, prepared via the vulcanization process using some special vulcanization accelerators and the melt compounding process with a liquid-low molecular weight EPDM. Not many reports are available for EPDM-clay matrices prepared using solution-intercalation especially kaolinite as filler.

In the present work, EPDM-kaolinite composites have been prepared by solution-intercalation method using 
dicumyl peroxide as curing agent and the morphology of the composites studied using FT-IR, W-XRD, and SEM techniques. The mechanical properties of EPDM reinforced with kaolinite and virgin EPDM have also been compared.

\section{Experimental}

Materials

EPDM rubber sample pack was obtained from DupontDow. Kaolinite powder with $20-50 \mu \mathrm{m}$ average thickness was obtained as an industrial product from SanXing HighNew Material Company of Zaozhuang in China. Toluene and xylene were supplied by $\mathrm{CDH}$, New Delhi. Double distilled water was used throughout the study.

Preparation of EPDM/CA-MMT nanocomposites

Varying amount of kaolinite (1, 3, 5 and $7 \mathrm{phr}$ ) was added to EPDM rubber $(16 \mathrm{~g})$ dissolved in toluene $(300 \mathrm{~mL})$ in a three-necked flask $(500 \mathrm{~mL})$ and ultrasonicated for perfect dispersion. The contents were mechanically stirred for $5 \mathrm{~h}$ at $60^{\circ} \mathrm{C}$, cured by adding dicumyl peroxide $(3 \mathrm{phr})$ just

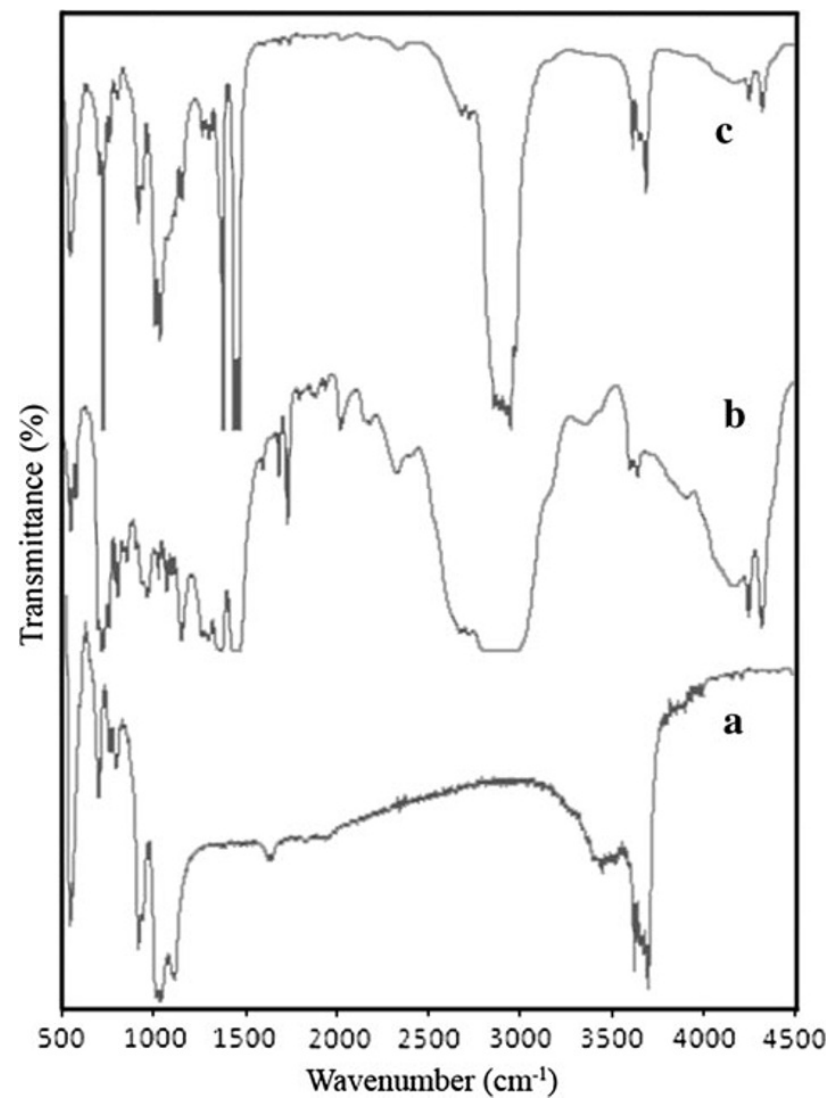

Fig. 1 FT-IR spectra of a kaolinite, b EPDM, and $\mathbf{c}$ kaolinite-filled EPDM
4-5 min before completion of heating and immediately transferred into glass moulds when thin films of the nanocomposite were obtained, by dipping the mould into water, after extracting the solvent.

\section{Characterization}

The Fourier transform infrared (FT-IR) spectra were recorded on a Nicolet spectrophotometer model Nexus-670 in the range of $400-4,500 \mathrm{~cm}^{-1}$. X-ray diffraction patterns were obtained using an X-Pert pro diffractometer, with $\mathrm{Cu} \mathrm{K} \alpha$ radiation. Tensile tests were performed using INSTRON 3365, UK, as per ASTM-D3039 standards with a cross head speed of $100 \mathrm{~mm} \mathrm{~min}^{-1}$. The surfaces were coated with gold and examined under a scanning electron microscope (CARL-ZEISS, Model EVO-50).

\section{Results and discussion}

Morphological studies

The morphological studies were performed using FT-IR, XRD and SEM techniques. Figure 1 depicts the IR spectra of kaolinite (1a), EPDM (1b) and kaolinite-filled EPDM

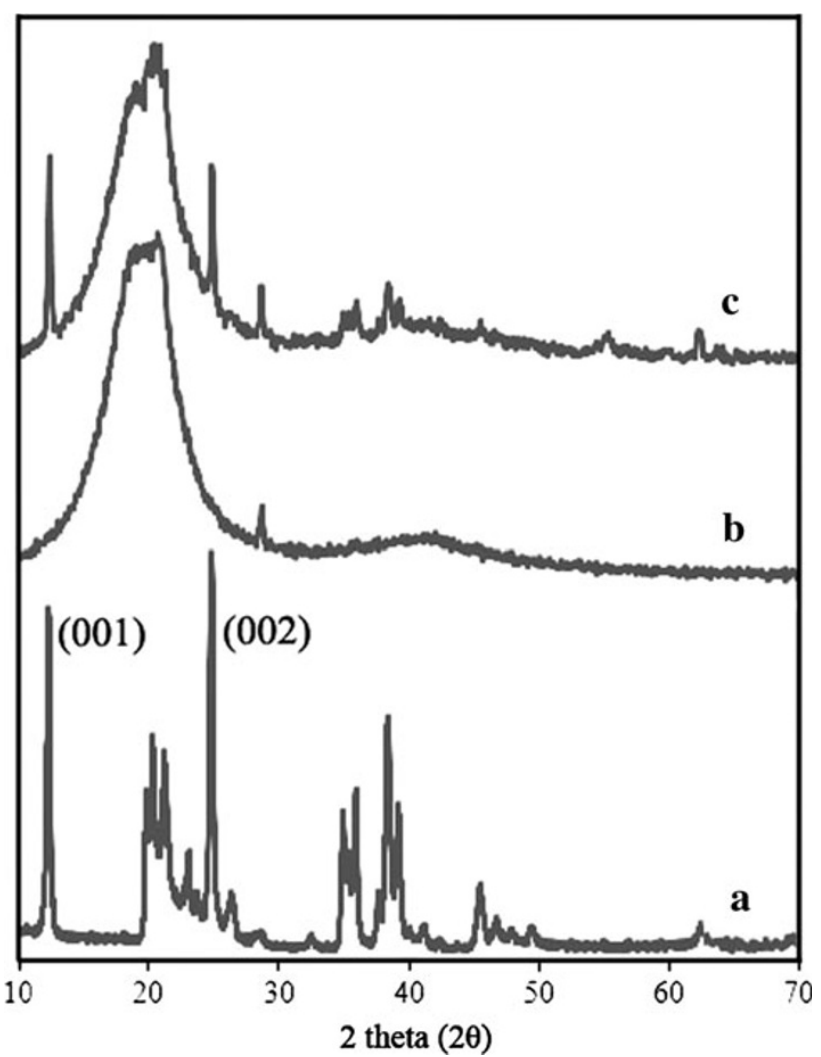

Fig. 2 XRD pattens of a kaolinite, b EPDM, and $\mathbf{c}$ kaolinite-filled EPDM 
(1c). The peak at $3,620 \mathrm{~cm}^{-1}$ refers to the inner $\mathrm{O}-\mathrm{H}$ stretching, while the $3,710 \mathrm{~cm}^{-1}$ peak corresponds to the in-phase stretching of the three inner-surface $\mathrm{O}-\mathrm{H}$ groups, and the signals at 3,669 and $3,652 \mathrm{~cm}^{-1}$ are due to the antiphase stretching modes of the inner-surface $\mathrm{O}-\mathrm{H}$ groups. The absorption at 1,008 and $1,032 \mathrm{~cm}^{-1}$ could be attributed to the anti-symmetric stretch of equatorial $\mathrm{Si}-\mathrm{O}$ bonds (Etienne Balan et al. 2001). The in-phase stretch of apical $\mathrm{Si}-\mathrm{O}$ bonds appears on the spectrum at $1,134 \mathrm{~cm}^{-1}$ and the band at $1,090 \mathrm{~cm}^{-1}$ corresponds to the symmetric stretch of equatorial $\mathrm{Si}-\mathrm{O}$ bonds. The absorption band at $1,090 \mathrm{~cm}^{-1}$ is characteristic of kaolinite. After processing, kaolinite-filled EPDM exhibited the characteristic bands at 1,090 and $3,710 \mathrm{~cm}^{-1}$ which were absent in the virgin EPDM. This confirms the presence of kaolinite layers within EPDM matrix. Also, the difference in absorption of virgin EPDM and kaolinite-filled EPDM at 2,700-3,000 $\mathrm{cm}^{-1}$ shows a definite morphological change.

Figure 2 depicts the X-ray profile of kaolinite (2a), EPDM (2b), and the kaolinite-filled EPDM (2c). The basal spacing of (001) and (002) planes are $7.214 \times 10^{-1}$ and $3.587 \times 10^{-1} \mathrm{~nm}$, respectively, showing the characteristic peaks of kaolinite in Fig. 2a, c. The absence of other characteristic diffraction peaks of kaolinite in Fig. 2c between $20^{\circ}-25^{\circ}$ and $35^{\circ}-40^{\circ}$ goes to prove the special directional and parallel arrangements of kaolin platelets within the rubber matrix, consistent with the dispersed pattern observed from the SEM technique. Further, the EPDM polymer has also intercalated between the layers of the kaolinite as shown by the increase in d-spacing with the consequent shifting of $2 \theta$ value (24.97-24.73) (Qinfu Liu et al. 2008).

SEM images given in Fig. 3 clearly depict the even distribution of clay particles in the matrix and also the possible clay layers in nano-scale with a little agglomeration.

\section{Mechanical properties}

The mechanical testing was performed on the EPDM/ kaolinite clay matrices under different filler content and the variation in tensile strength (Fig. 4) shows that there is a small increase of tensile strength until $3 \%$ clay content and thereafter gets doubled for $7 \%$ kaolinite-filled composites. The 7\% clay-filled matrix has shown more than a twofold increase in tensile strength compared to the neat EPDM.

Figure 5 shows the effect of filler content on elongation at break. Elongation at break of the EPDM films initially
Fig. 3 SEM images of a virgin EPDM, b 1 wt $\%$ kaolinite-filled EPDM, c, d 5 wt $\%$ filled EPDM
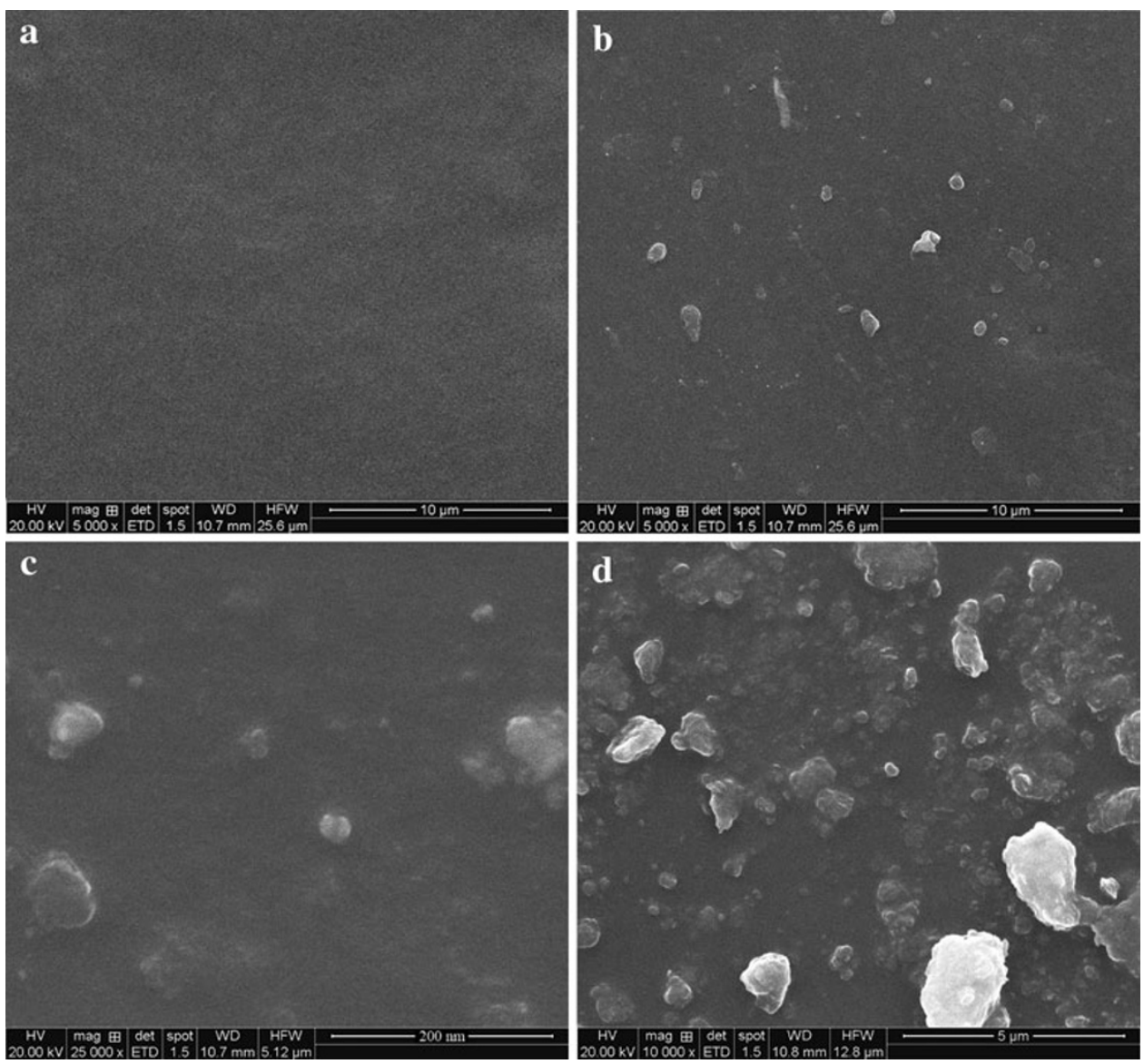

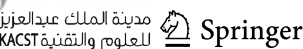




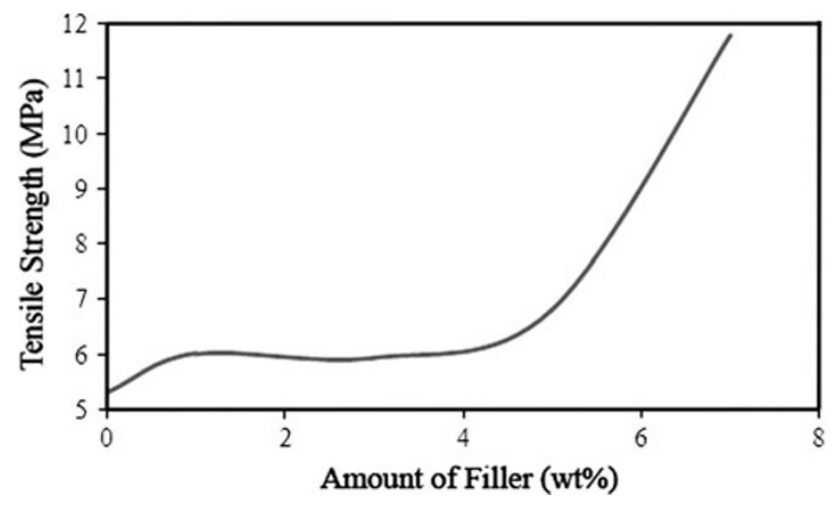

Fig. 4 Tensile strength versus amount of kaolinite



Fig. 5 Elongation at break versus amount of kaolinite

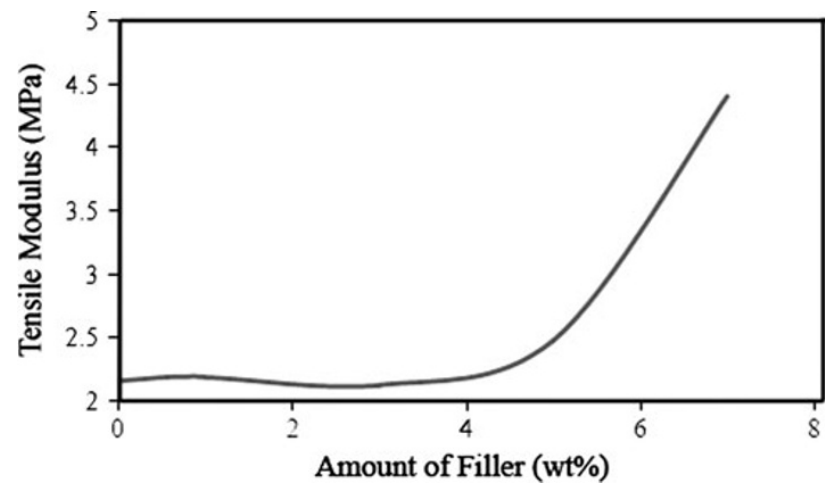

Fig. 6 Tensile modulus versus amount of kaolinite

decreases with kaolinite content and then shows a steady increase. This increase may be attributed to the possible intercalation of the rubber polymer chains within the clay matrices.

The tensile modulus of the composites also shows a similar scenario as that of the tensile strength (Fig. 6). The enhancement in tensile strength and tensile modulus is the direct manifestation of the dispersion of kaolinite layers in the EPDM matrix and the strong interaction between EPDM and kaolinite clay (Seyed Javad Ahmadi et al. 2005) is further confirmed by the increased d-spacing in the XRD patterns of the EPDM/kaolinite composites.

Comparing this result to the mechanical properties of cetyl ammonium modified montmorillonite (CA-MMT) filled EPDM obtained in our previous work, the tensile strength of 5\% CA-MMT filled EPDM is $11.17 \mathrm{MPa}$ which is attained here by $7 \%$ kaolinite filled EPDM. The tensile modulus of 5 wt $\%$ CA-MMT-filled EPDM is 3.37 but those of 5 and $7 \%$ kaolinite filled EPDM are 2.48 and 4.41, respectively.

\section{Conclusion}

The morphological studies of the EPDM/kaolinite composites indicate the uniform dispersal of the clay particles with possible intercalation of clay layers. The kaolinite composites have superior mechanical properties compared to those of the neat resin. The enhanced characteristics are attributed to the uniform dispersal of the clay particles in the polymer matrix. Reinforcing higher proportion of kaolinite in the polymer matrix could match the high quality of MMT-filled EPDM vis-à-vis the mechanical properties. The abundance of kaolinite in this part of the country could be an efficient substitute in chosen aspects of using MMT clay as filler in polymer matrices.

Open Access This article is distributed under the terms of the Creative Commons Attribution License which permits any use, distribution and reproduction in any medium, provided the original author(s) and source are credited.

\section{References}

Agag T, Koga T, Takeichi $\mathrm{T}$ (2001) Studies on thermal and mechanical properties of polyimide-clay nanocomposites. Polymer 42(8):3399-3408

Ahmadi SJ, Huang YD, Li W (2005) Morphology and characterization of clay-reinforced EPDM nanocomposites. J Compos Mater 39(8):745-754

Balan E, Saitta AM, Mauri F, Calas G (2001) First-principles modeling of the infrared spectrum of kaolinite. Am Mineral 86:1321-1330

Chang YW, Yang Y, Ryu S, Nah C (2002) Preparation and properties of EPDM/Organo-montmorillonite hybrid nanocomposites. Polym Int 51(4):319-324

Giannelis EP (1996) Polymer layered silicate nanocomposites. J Adv Mater 8:29-35

Hasegawa N, Kawasumi M, Kato M, Usuki A, Okada A (1998) Preparation and mechanical properties of polypropylene-clay hybrids using a maleic anhydride-modified polypropylene oligomer. J Appl Polym Sci 67(1):87-92

Hasegawa N, Okamoto H, Kato M, Usuki A (2000) Preparation and mechanical properties of polypropylene-clay hybrids based on modified polypropylene and organophilic clay. J Appl Polym Sci 78(11):1918-1922

Kato M, Usukai A, Okada A (1997) Synthesis of polypropylene oligomer-clay intercalation compounds. J Appl Polym Sci 66(9):1781-1785 
Kawasumi M, Hasegawa N, Kato M, Usuki A, Okada A (1997) Preparation and mechanical properties of polypropylene-clay hybrids. Macromolecules 30(20):6333-6338

Kojima Y, Usuki A, Kawasumi M, Okada A, Fujushima A, Kurauchi T, Kamigaito O (1993) Mechanical properties of nylon 6-clay hybrid. J Mater Res 8(5):1185-1189

Lan T, Pinnavaia TJ (1994) Clay-reinforced epoxy nanocomposites. J Chem Mater 6:2216-2219

Liu Q, Zhang Y, Xu H (2008) Properties of vulcanized rubber nanocomposites filled with nanokaolin and precipitated silica. Appl Clay Sci 42:232-237

Messersmith PB, Giannelis EP (1993) Polymer-layered silicate nanocomposites: in situ intercalative polymerization of $\varepsilon$-caprolactone in layered silicates. Chem Mater 5(8):1064-1066
Uhl FM, Wilkie CA (2002) Polystyrene/Graphite nanocomposites: effect on thermal stability. Polym Degrad Stab 76(1):111122

Usukai A, Tukigase A, Kato M (2002) Preparation and properties of EPDM-clay hybrids. Polymer 43(8):2185-2189

Usuki A, Kojima Y, Kawasumi M, Okada A, Fujushima A, Kurauchi T, Kamigaito O (1993) Synthesis of nylon-6-clay hybrid. J Mater Res 8(5):1179-1183

Whittingham MS, Jacobson AE (1982) Intercalation chemistry. Academic Press, New York 